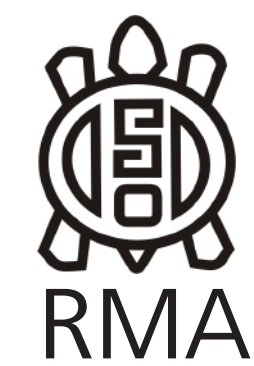

Antropología Social

\title{
Los caminos del guerrero Entrevista con Denise Y. Arnold
}

\author{
Entrevista y comentarios por Francisco Pazzarelli*
}

* Instituto de Antropología Córdoba, CONICET. Facultad de Filosofía y Humanidades, Universidad Nacional de Córdoba

Email: fpazzarelli@hotmail.com

Denise Y. Arnold. Instituto de Lengua y Cultura Aymara (ILCA), La Paz, Bolivia / Birkbeck College London, University of London, Londres.

The warriors' paths. Interview with Denise Y. Arnold

Denise Y. Arnold, reconocida antropóloga andinista, especialista en el área aymara boliviana, autora de más de veinte libros y una centena de ensayos, muchos de ellos en colaboración con Juan de Dios Yapita, divide su tiempo entre La Paz y Londres. En La Paz, dirige el Instituto de Lengua y Cultura Aymara (ILCA), que desde hace ya varios años se posiciona como uno de los centros de producción intelectual referentes del área andina, con una importante proyección regional e internacional. En Londres, dirige y participa de distintos proyectos vinculados actualmente al estudio de las técnicas textiles andinas, en Birkbeck College London, de la University of London. Estos caminos, entre Suramérica y Europa, sin duda colaboraron a definir buena parte de sus preocupaciones e intereses de investigación, pero son quizá los "caminos guerreros" que se trazan desde Qaqachaka aquellos que mejor permiten remontar hoy sus preguntas y búsquedas. Sabemos que Denise no sólo ha conseguido llamar la atención sobre temas en su momento poco estudiados (como la arquitectura "vernácula" del Altiplano), sino que lo ha hecho en colaboración con distintas personas de las comunidades "estudiadas", junto a las cuales escribió numerosos artículos y libros. Además, lejos de invisibilizar su participación en proyectos de desarrollo, su producción plantea explícita y críticamente la necesidad de la intervención de los antropólogos, que en esta entrevista define como "abrir los estudios antropológicos a temas reales". Esto no impidió (muy por el contrario) un desarrollo teórico consistente, cuyos desenlaces actuales se caracterizan por haber logrado articulaciones teórico-interpretativas con los debates antropológicos de otras regiones de América, especialmente con tierras bajas y Amazonía.

Mediante distintos desplazamientos intelectuales (que muchos considerarian como arriesgados) y una buena dosis de "imaginación conceptual" (para parafrasear a Eduardo Viveiros de Castro), buena parte de la producción actual de Denise se ha ocupado de llevar hacia los Andes algunas de las preocupaciones que parecían "típicas" de tierras bajas, logrando acceder a las interpretaciones andinas de conceptos y categorías que parecían ajenos a las tierras altas. Así, nociones como "depredación ontológica" o "apropiación de subjetividades" devinieron parte de explicaciones que lentamente comenzaron (y continúan cada vez más) cobrando sentido en los Andes. Todo ello, claro, en el marco de la impronta etnográfica que caracteriza su producción, que se define por una densidad descriptiva y analítica (en español y en aymara, la mayoría de las veces) que no siempre es fácil de encontrar.

En esta entrevista, realizada en una tarde de primavera en la biblioteca de ILCA, en La Paz, Denise señala los tambos de sus recorridos y desenrolla las madejas de algunas de sus propuestas más difundidas, recordando decisiones, azares, alegrías, frustraciones y develando también las razones que hacen imprescindible continuar con el estudio de sus ideas.

Francisco Pazzarelli (FP): Reconstruyendo un poco su historia, sabemos que usted estudió primero Arquitectura y Ciencias del Ambiente. Luego de eso ¿cómo es que llegó a la Antropología?

Denise Y. Arnold (DYA): Sí, estudié Arquitectura. Me gustaba y tuve la oportunidad de trabajar con algunos arquitectos excelentes en Inglaterra ipero era muy frustrante intelectualmente! (risas). Los arquitectos tienen cierta pomposidad y a veces un lenguaje un poco rebuscado sobre la relaciones entre la arquitectura y la sociedad. Tenía la posibilidad de optar por estudiar Historia del Arte y eso hubiera sido una solución. Pero tampoco quería encerrarme en una oficina, amarrada dos o tres años con un sólo proyecto. Quería viajar y ver el mundo. Hubo un curso en University College, en Londres, en la escuela de arquitectura, enseñado por geógrafos, antropólogos y lingüistas. Era una Maestría en Medio Ambiente, pero en realidad era una oportunidad para re-formarse y actualizarse en vías de entrar en el mundo 
académico. Fue fascinante: uno tenía que aprender cómo hacer una tesis con referencias académicas bien escritas en un mes. Eso me dio la oportunidad de escribir dos ensayos largos: uno sobre la organización social y espacial de los pueblos Hopi del Suroeste de los EEUU y otro sobre los aborígenes de Australia, centrándome en los nexos entre sus sistemas de parentesco y el uso del territorio. Luego, como tesis de Maestría hice un ensayo que tomó como punto de partida el estudio reciente de Pierre Bourdieu de la casa bereber ${ }^{1}$, que en aquellos años era toda una novedad, estamos hablando del año 1978. Siempre supe que quería estudiar antropología, pero era difícil hacerlo directamente sin contar con la licenciatura. Entonces, con la Maestría en Medio Ambiente pude pasar directamente al nivel de Doctorado en Antropología y no perder el tiempo en otros niveles. En aquellos años pude oír las clases de Mary Douglas, Andrew Strathern, Mike Gilsenan y Mike Rowlands. Con vistas hacia la tesis, comencé a estudiar las tierras bajas de Amazonas, con Stephen Nugent. Steve es marxista, es músico de jazz, sabe escribir muy bien e incluso escribía la vida de Jimmy Hendrix como ghost writer. Es un hombre muy amplio y no me imponía nada sobre las formas de investigar o escribir. Él quiso siempre que yo trabajara en la región de [Michael] Taussig, en los bordes del río Madre de Dios, con el tema del boom de la producción de caucho y quinina; y leí bastante sobre eso. Llegué a La Paz, para entrar a la selva de Bolivia, pero me he encontrado con Juan de Dios Yapita ${ }^{2}$ y con el mundo aymara... iy así es como he llegado a estudiar en los Andes! Claro, había leído los trabajos de mis colegas ingleses, Tristan Platt, Olivia Harris, del holandés Tom Zuidema, y los Andes habían sido tema de uno de mis ensayos largos de maestría. Pero la mayor parte de mis lecturas estaban dirigidas a las tierras bajas. Asistí a las clases de Joanna Overing y colegas, y me sentía un poco infiel entre los andinistas... Pero por esa razón pude ver de forma distinta algunas cosas tomadas por sentado en los Andes. No tuve preconcepciones por haber tenido clases dirigidas o un supervisor dogmático y muy metido en lo andino. Yo tenía que leer los textos que se me ocurrían y aprender los temas de esa región gradualmente. Lleva más tiempo sin tener un supervisor muy metido en la misma área, pero me permitía tener cierta independencia de pensamiento. Luego, al completar mis estudios, sentí cierta obligación con mi primera profesión de arquitecta, porque te da una manera de ver el mundo... Entonces, el primer artículo que escribí fue sobre la construcción y el significado

\footnotetext{
1 Se refiere a: Bourdieu, P. 2010 [1970]. La casa o el mundo dado vuelta. El sentido práctico: 419-437. Siglo Veintiuno Editores, Buenos Aires.

2 Juan de Dios Yapita Moya, además de compañero de Denise desde sus primeros momentos, es lingüista, especialista en el estudio y en la enseñanza del aymara, reconocido tanto en el ámbito boliviano como en los círculos internacionales. Participó de la creación de la Carrera de Lingüística e Idiomas (con mención en aymara y quechua) de la Universidad Mayor de San Andrés (La Paz) y fue el fundador del ILCA, en el cual se desempeñó como director durante varios años.
}

cosmológico de la casa aymara en los Andes ${ }^{3}$, emulando los ensayos clásicos de Johannes Wilbert y otros de la época. En aquel entonces, hablé por primera vez con Xavier Albó sobre las casas tradicionales del Altiplano, pero él quería una solución desarrollista: reemplazar los techos con calaminas ${ }^{4}$ y exterminar las vinchucas: ¡hemos peleado desde el inicio! (risas). Después de eso, quise distanciarme de la arquitectura y dedicarme full a la antropología... Antes del trabajo de campo no eres considerado realmente un antropólogo y recién con eso te aceptan como colega y en las universidades.

FP: Es un rito de paso, ¿no? ¿Cómo fue, entonces, su entrada en el campo etnográfico boliviano?

DYA: Me encontré con Ramiro Molina... y también estaba aquí realizando su trabajo de campo Cassandra Torrico, sobre el tema de los textiles. Ella estaba trabajando desde hacía muchos años en Macha y desarrollamos una amistad que dura hasta ahora. Me invitaba a visitarla en la comunidad pastora de Tumaycuri, en el Norte de Potosí. Tenía que caminar horas y horas entre los cerros para llegar, encima del mundo. Allí experimenté por primera vez el penetrante frío de las montañas. Ramiro me dijo que entre los ayllus donde no había investigaciones estaba Qaqachaka. Lo visité con una mujer de pollera ${ }^{5}$, Emiliana Ilaya, de la oficina del Instituto de Lengua y Cultura Aymara, donde trabajaba Juan de Dios Yapita, y vimos que era muy interesante. Llamaba la atención que Emiliana, de la parte lacustre de La Paz, no podía entender bien el aymara de esa región. Juan de Dios tenía curiosidad de conocer el lugar y nos pusimos a explorar juntos esta variante regional del aymara. Así fue la entrada... coincidencias, una suerte de encuentros. Compartía mucho mis ideas con Cassandra y las comparábamos con el mundo quechua que ella conocía. Además, en aquellos años La Paz era mucho más interesante que ahora. Había talleres cada semana organizados por Verónica Cereceda y su esposo Gabriel Martínez, aquí cerca en Sopocachi ${ }^{6}$.

\footnotetext{
3 Se refiere a su clásico artículo "La casa de adobe y piedras del Inka: género, memoria y cosmos en Qaqachaka", publicado en 1996 en su compilación Hacia un orden andino de las cosas (libro sobre el que se refiere más adelante). "La casa..." sigue siendo citado como un artículo de referencia al momento de pensar y analizar el mundo de la construcción en los Andes, y en él se definen muchos de los intereses que desarrollaría en trabajos posteriores: el mundo de las técnicas, la cultura material y las multirreferencialidad del textil (y de sus técnicas) como esquema organizador de significados.

4 Por "calaminas" se refiere a las chapas acanaladas, de zinc, utilizadas para techar casas.

5 Mujer de pollera es una expresión común en Bolivia para referir a aquellas mujeres que visten las coloridas polleras "típicas" de las zonas rurales indígenas (aunque vivan en ciudades); en contraposición, la expresión mujer de vestido refiere a aquellas que visten de un modo más citadino (aunque vivan en el campo). En muchas ocasiones, ambas expresiones pueden utilizarse para señalar el "cambio de vida" de mujeres que salieron del campo y, por distintas situaciones, dejaron sus polleras para comenzar a usar vestido.

6 Sopocachi es un barrio de la ciudad de La Paz, donde actualmente se encuentra el ILCA.
} 
Uno podía abrir los ojos y ver quién era quién. Eran excelentes, algo que nunca más tuvimos, nada así en los últimos 20 o 30 años. Hablé con Verónica de mis ideas. Yo quería comparar el arte de los aborígenes haciendo mapeos del espacio con los textiles andinos. Pero ella resistía esta sugerencia defendiéndose con "lo andino" de la época: "No, no, no hay que imponer nada sobre el mundo andino, es totalmente diferente a todo el resto del mundo". Yo iba trabajando solitariamente con mis intereses personales para saber cómo era la vida de las mujeres, cómo era el mundo de los textiles... Hice mi tesis doctoral sobre temas convencionales como el parentesco, pero quise regresar inmediatamente después de terminarla y aprender mucho más sobre los Andes. Por esta razón nunca entré en el mundo académico con un puesto permanente en mi país. Quería investigar e investigar hasta cansarme. Pasaron muchos años antes de que pudiera volver libremente a esas ideas y explorar los textiles andinos con más profundidad. Parentesco era un problema para mi tema de tesis, pero en esa época había una nueva ley impositiva sobre tierras y era imposible hablar directamente con los comunarios sobre las tierras que les pertenecían; eran muy susceptibles. Esa fue la razón por la que entré al estudio de parentesco a través del mundo ritual de la papa7. Tuve que dar una vuelta muy grande para llegar a eso, pero tenía la ventaja de ir trabajando con Juan de Dios... Siempre era difícil trabajar en Qaqachaka. Son guerreros con cierta bravura y gozaban con asustarnos y ver cómo nos asustábamos. Tenías que aprender a adquirir esa misma bravura y no asustarte. ¡Es parte del aprendizaje del camino del guerrero! He aprendido mucho con ellos (risas).

\section{FP: ¿Cuánto tiempo vivieron en Qaqachaka?}

DYA: Fueron dos años para hacer el doctorado, pero me daba cuenta de que en dos años había aprendido muy poco. Simplemente lo necesario para hacer una tesis en los términos de la Universidad, con introducción, desarrollo, conclusión y capítulos. Lo hice como una formalidad, sabiendo que tenía que regresar y con calma tratar de entender la región. Por eso inmediatamente apliqué a una beca posdoctoral para regresar.

\section{FP: ¿Y cuando regresó ya se quedaron aquí?}

\section{DYA: Sí. Hubo un momento en que estuvimos en King's}

\footnotetext{
7 Al respecto, puede consultarse Arnold, D. y J. D. Yapita. 1998. Madre Melliza y sus crías (Ispall Mama Wawampi): Antología de la papa. Hisbol-ILCA, La Paz. Madre melliza... describe y analiza el mundo ritual vinculado a la siembra, cosecha, consumo (y otros manejos) de las papas en el Altiplano. Buena parte del libro se dedica a la exégesis de cuentos vinculados a los orígenes míticos de las papas, junto con la reproducción y análisis de una conversación en aymara, sobre la metafísica de la papa, entre Juan de Dios Yapita y Don Jiménez Aruquipa, un yatiri (sabio) del norte de Potosí. Entre los ensayos que completan el volumen se destaca "La papa, el amor y la violencia. La crisis ecológica y las batallas rituales en el linde entre Oruro y norte de Potosí", que analiza los conflictos entre ayllus en el marco general de la metafísica de las papas que presenta el libro.
}

College, en Londres, dictando cursos, con seis meses en Bolivia y seis meses en Londres. Después tuve otra beca. Moviéndonos entre los dos lados era muy difícil, sobre todo en aquellos años cuando uno tenía que llevar libros y cuadernos de campo muy pesados en el vuelo, era chistoso viajar (risas).

FP: Esto fue a fines de los '80 y principios de los ‘90, ¿no?

DYA: Sí, era muy diferente en aquellos años... Incluso tampoco había formación en métodos, yo no tuve. Aquí en Bolivia, no sé cómo será en Argentina, pero aquí todo es métodos, métodos, metodologías, más que cualquier otro tema. En Londres, en aquellos años, no había cursos de métodos, ni aprendizaje de lenguas ¡nada! Te dejaban sola. El modelo vigente era el de la escuela privada en Inglaterra: te mandaba al mundo salvaje, el boarding school $^{8}$ era como el campo y tenías que aprender a sobrevivir. Era duro, pero se aprende de por sí que el método es lo que tú desarrollas para realizar el análisis y para expresar todo lo que has visto y leído, pero con tu propia voz.

FP: ¿Recuerda en aquellos años en Inglaterra alguien que la haya marcado en su formación?

DYA: En University College estaban Mike Rowlands y Danny Miller en estudios de cultura material y era excelente hablar con ellos. Hubo también un grupo de africanistas... En clases de maestría con Warwick Bray conocí también al grupo de arqueólogos que trabajaban en América Latina: Bill Sillar, Colin McEwan. El único estudiante que trabajaba aquí en Bolivia era Anthony Henman, que escribió el libro Mama Coca ${ }^{9}$. Yo andaba con él, era el único estudiante con quien podía conversar. Me contaba de la selva y de sus experiencias con alucinógenos.

\section{FP: ¿Su tesis doctoral fue en el '88?}

DYA: Sí. Tenía que trabajar como arquitecta para ganar dinero y escribí la tesis en las noches. Tuve una pequeña Beca Radcliffe-Brown, que eran unos 300 dólares, una suma muy pequeña hoy, pero me daba tres meses para terminar mi tesis.

FP: Y cuatro años después, en el '92, se publica Hacia un orden andino de las $\cos ^{10}{ }^{10}$, un libro que tuvo un

\footnotetext{
8 Boarding school refiere a las escuelas inglesas, en su mayoría privadas, en donde los estudiantes vivían como pupilos.

9 Henman, A. 1992. Mama Coca. Hisbol, La Paz.

10 Denise A., D. Jiménez Aruquipa y J. D. Yapita. 1992. Hacia un orden andino de las cosas: tres pistas de los Andes meridionales. HISBOLILCA, La Paz (cuenta con una segunda edición en 1998). En este volumen, además del mencionado artículo dedicado a "La casa...", se incorporan los ensayos "Simillt'aña...", en donde se describen y analizan las canciones dedicadas a los alimentos en los ayllus aymaras, y "Salqa...", donde se indagan los sistemas clasificatorios que operan sobre los animales salvajes, a través de una exégesis de distintos
} 
impacto enorme.

DYA: ¡Tanto que hasta ahora la gente pide que se reedite! El problema es que estamos conscientes de que ese libro es una expresión simple de las cosas...

FP: Pero en su momento tuvo una gran importancia y todavía la tiene. Al respecto, uno de los objetivos enunciados en la Introducción era el de comprender y seguir "las consecuencias lógicas de los sistemas locales de conocimiento y práctica, en lugar de reinterpretarlos según teorías extrínsecas y globales". Esto creo que ha marcado su producción hasta la actualidad y es una discusión que me recuerda al Ilamado que hacía Joanna Overing, a mediados de los '70, cuando reclamaba un nuevo lenguaje para pensar Amazonía, uno que no fuera deudor de la antropología africanista o melanesista ${ }^{11}$. ¿Cómo fue su relación con Joanna y su grupo?

DYA: Yo andaba en Londres, tenía mi bicicleta y andaba por todos lados: trabajaba a medio día en una oficina de arquitectos e hice tres maestrías en las noches, ¡me fascinaba! Asistí a las clases de maestría de Joanna, que eran excelentes, y allí me encontré con Peter Gow, Penny Harvey, Els Lagrou... y mediante ellos con Eduardo Viveiros de Castro, Aparecida Vilaça, Philipe Descola y Anne-Christine Taylor. Era muy liberador. Leímos el libro Transformations of the hummingbird, de Eva Hunt ${ }^{12}$, sobre Mesoamérica, y textos sobre la selva. Eso nos abría los ojos a una nueva manera de pensar y ha debido tener su impacto en mi trabajo. Luego tuvimos una amistad personal con Joanna, cuando ella estaba en la Universidad de Saint Andrews, en Escocia. En ese momento, era un centro de estudios andinos y su director era Douglas Gifford, un hombre extraordinario que era cura, músico, pintor, quechuista. En aquellos años se contaba también con una presencia de estudios mesoamericanos y conocí por primera vez a Gordon Brotherston. Luego Douglas Gifford murió de repente y Tristan Platt entró como Director. Bajo Joanna, [Saint Andrews] se había convertido en un centro de estudios amazónicos, pero siempre hacían puentes entre las tierras altas y bajas. Su casa se llenaba constantemente de estudiantes y visitas de todo el mundo, era una inspiración. En años posteriores, Juan de Dios enseñó aymara en las universidades de Florida, Cornell y Berkeley. Conocimos al grupo en torno a Martha Hardman, John Murra y Tom Zuidema: Gary Urton, Billie-Jean Isbell, Frank Salomon. Y en Berkeley, a John

cuentos. Esta trilogía permite ordenar distintas piezas claves del pensamiento lógico andino y constituye una referencia indispensable para la lectura de su obra posterior.

11 Me refiero a las discusiones que se generaron en el ámbito del Congreso Internacional de Americanistas de 1977, en el simposio "Social Time and Social Space in Lowland South American Societies", organizado por Joanna Overing (Publicado en: Actes du XLIle Congrès International des Américanistes, II: 7-394. Paris).

12 Hunt, E. 1977. The Transformation of the Hummingbird: Cultural Roots of a Zinacantecan Mythical Poem. Cornell University Press, Cornell.
Rowe, su esposa Patricia Lyons, y a Christine Hastorf. La otra tendencia que me influyó fue la de los nexos entre literatura y lingüística, que leí bastante en el contexto de los trabajos con Juan de Dios sobre la tradición oral de los Andes. Conocí a Lucy Briggs, Bruce Mannheim, y luego a William Rowe y Rosaleen Howard, que son amigos hasta ahora.

FP: ¿Y cree que aquí se ha logrado desarrollar un lenguaje que permita explicar a los Andes en sus propios términos? ¿Somos deudores de los lenguajes materialistas y del campesinado clásico?

DYA: Creo que una de las mayores influencias en la construcción de este lenguaje alternativo, más allá de las del campesinado clásico, venía del nexo literaturalingüística y no tanto de la antropología. Hoy en Bolivia hay un desconocimiento de aquella tendencia y se ha optado, por razones políticas, por analizar todo según las políticas identitarias y del indigenismo, incluso del nativisimo del tipo New Age. Hay un colapso intelectual desde 2005 y uno ya no puede hablar de estudios regionales o "de los Andes". Aunque a nivel mundial hay una producción intelectual centrada en los Andes todavía: hay autores como Andrew Canessa, Robert Albro, Anthony Bebbington y Bret Gustafson, quienes también toman sus fuentes de información de otras áreas de estudio. Entonces, mi respuesta sería sí: se ha podido desarrollar un lenguaje propio, pero quizá no está desarrollado tanto como en el caso de Melanesia u otras partes del mundo, donde se siente mucho el impacto de personas como Marilyn Strathern. Para mí personalmente fue la escritura del libro El rincón de las cabezas ${ }^{13}$ lo que me ha permitido percibir los estudios andinos de otra manera. Allí pude iniciar una comparación entre los Andes y el mundo amazónico, recurriendo a las ideas de Carlos Fausto y de Eduardo Viveiros de Castro sobre la depredación ontológica. Después de ese momento, analizo las cosas de otra manera iy desde entonces las

\footnotetext{
13 Arnold, D. y J. D. Yapita. 2000. El rincón de las cabezas. Luchas textuales, educación y tierras en los Andes. Universidad Mayor de San Andrés-ILCA, La Paz. Concebido en el marco de una evaluación de lo que estaba siendo la Reforma Educativa en Bolivia, a fines de los '90 e inicios del 2000, la publicación de El rincón de las cabezas... causó mucho revuelo en el contexto boliviano y su circulación fue reducida. En 2005 se logra una reedición, actualizada y corregida. No era para menos. El libro, lejos de dedicarse a un estudio comparativo del antes y después de la Reforma, coloca a los nuevos contenidos educacionales en el marco de las historias de larga duración en los Andes, lo que permite descubrir las similitudes entre los intentos coloniales de educación indígena y los actuales. Todo ello con la necesidad de explorar las formas locales de conocimiento (no sólo qué se conoce sino cómo se lo conoce). Es en esta articulación, triangulada con los ciclos y flujos de producción y fertilidad en los Andes, donde las cabezas (su adquisición y manipulación) comienzan a aparecer por todos lados y proporcionan las herramientas que permiten abordar y comprender la intelectualidad indígena. En este contexto, la referencia a ideas y conceptos "amazónicos" permite terminar de dar forma a un modelo andino de la depredación que seguirá siendo desarrollado en ensayos posteriores. El libro tiene una versión en inglés: Arnold, D. y J. D. Yapita. 2006. The Metamorphosis of heads: Textual Struggles, Education and Land in the Andes, University of Pittsburgh Press.
} 
cabezas trofeo aparecen por todos lados! Para mí, aquel libro fue clave para relacionar las tierras altas y las tierras bajas, el pasado, el presente y el textil... para repensar el lenguaje simbólico.

FP: Es una apuesta interesante, porque en general muchos sostienen que existe una discontinuidad ontológica entre los Andes y Amazonía; hay ideas que no se comparten, marcos de interpretación que no circulan.

DYA: Este nexo entre las tierras altas y bajas está allí desde los años '80, con los libros L'Inca, I'Espagnol et les sauvages y Al este de los Andes. Relaciones entre las sociedades amazónicas y andinas entre los siglos XV y XVII, de Renard-Casevitz, France-Marie, Thierry Saignes y Anne-Christine Taylor ${ }^{14}$, y de Thierry Saignes: Los Andes orientales: historia de un olvido ${ }^{15}$. Thierry desgraciadamente ha muerto joven y la tendencia de lo "andino" ha podido dominar. Desde entonces, hubo un problema en la construcción de lo "andino" del que nunca se ha podido escapar. A mi modo de ver, una mala lectura del libro La identidad aymara ${ }^{16}$, de Thérèse Bouysse-Cassagne, también contribuyó al conjunto de clichés políticos actuales. Es como si no hubiera existido el ensayo crítico de Orin Starn ${ }^{17}$. La gente parece que no conoce esas cosas y sigue replicando los clichés de yanantin y chachawarmi ${ }^{18}$, como si fueran los grandes pilares y biblias de la región. Es realmente un problema. Además los planteamientos de algunos intelectuales han creado esencialismos de tal punto que han generado una sociedad muy fracturada y sin una dirección clara. Los estudiantes de Antropología de la Universidad Mayor de San Andrés, en La Paz, por lo menos se han dado cuenta de este problema intelectual de fondo que habría que tratar de resolver, pero no saben cómo... están todavía masticándolo.

FP: Teniendo en cuenta este desarrollo, ¿cómo devino su interés actual por los textiles, como "objeto" y como "sujeto" de análisis?

\footnotetext{
14 Renard-Casevitz, F. M., T. Saignes y A. C. Taylor. 1986. L'Inca, I'Espagnol et les sauvages. Rapports entre les sociétés amazoniennes et andines du xve au xviie siècle. Recherche sur les Civilizations, París. Y la versión en español, Renard-Casevitz, F. M., T. Saignes y A. C. Taylor. 1988. Al este de los Andes. Relaciones entre las sociedades amazónicas y andinas entre los siglos XV y XVII. Abya-Yala, Quito.

15 Saignes, T. 1985. Los Andes Orientales: historia de un olvido. Instituto Francés de Estudios Andinos-Centro de estudios de la realidad económica y social, Cochabamba.

16 Bouysse-Cassagne, T. 1987. La identidad Aymara: Aproximación histórica (Siglo XV, siglo XVI). Hisbol-Instituto Francés de Estudios Andinos, La Paz.

17 Se refiere a: Starn, O. 1990. Missing the Revolution: Anthropologists and the War in Peru. Cultural Anthropology 61: 63-91.

18 Yanantin es uno de los términos que mejor expresaría los conceptos de complementariedad en el mundo andino, mientras que chachawarmi referiría a una de las expresiones más importantes de esta lógica complementar: la que se daría entre hombre y mujer.
}

DYA: Me fascinaron siempre los textiles como cosas. Quería entender más sobre ellos, pero prontamente me di cuenta de que mis preguntas no llegaban a nada. Si uno no conoce la parte técnica, las mujeres no contestan. O te contestan como a una niña. Es como hablar de rocas sin saber de la geología...

FP: Como hablar de comida sin saber cocinar.

DYA: ¡Exactamente! Yo daba vueltas y vueltas. Tomé algunas clases de textil, porque me parecía el fundamento para poder entender los lenguajes visuales de la región, las codificaciones de economías y la producción, los sistemas de comunicación y todo lo demás. Leí bastante sobre el tema e hice algunos ensayos como el del wayñu ${ }^{19}$, pero fue al escribir el ensayo "Convertirse en persona" el tejido: la terminología aymara de un cuerpo textil, que está en una publicación en Barcelona ${ }^{20}$, que abrí mis ojos. Los textiles ya tenían su propia personalidad y eran sujetos en el mundo y no solamente objetos. Oía las voces dentro del textil y me daban fuerzas. Luego salieron muchos datos interesantes que me ayudaban a entender cómo funcionaba esa apropiación del otro dentro del textil ${ }^{21}$. Posteriormente, quise entrar con más profundidad en la parte técnica y tecnológica, porque es fascinante y te permite desarrollar las ideas acerca de cómo las mujeres mismas se forman como tejedoras, sobre cómo es su propio proceso de aprendizaje en la región. Con la tejedora Elvira Espejo ${ }^{22}$ hemos escrito tres libros: Ciencia de las mujeres ${ }^{23}$, de 2010, sobre la cadena productiva, Ciencia de tejer en los Andes ${ }^{24}$, de 2012, sobre las estructuras y técnicas de faz de urdimbre, y finalmente El textil tridimensional25, que está en prensa,

19 Arnold, D. 1992. En el corazón de la plaza tejida. El Wayñu en Qaqachaka. Anales de la Reunión anual de etnología. Museo Nacional de Etnografía y Folklore. MUSEF, La Paz. Y su versión en inglés, Arnold, D. 1992. At the heart of the woven dance-floor: the wayñu in Qaqachaka. Institut ur Iberoamerika-Kunde/Ibero-Amerikanisches Institut 16:21-66. Vervuert, Frankfurt.

20 Arnold, D. 2000. "Convertirse en persona" el tejido: la terminología aymara de un cuerpo textil. En Solanilla Demestre (ed.): Actas de la $1 \mathrm{a}$ Jornada Internacional sobre Textiles Precolombinos: 9-28. Servei de la Publication de la UAB, Barcelona.

21 En el análisis de la "apropiación del otro dentro del textil" es donde mejor se expresan los vínculos teóricos construidos por Arnold entre Andes y Amazonía. Al respecto, puede consultarse: Arnold, D. y J. D. Yapita. 2000. El rincón de las cabezas... op. cit., y Arnold, D., J. D. Yapita y E. Espejo Ayca. 2006. Hilos sueltos: Ios Andes desde el textil. Plural-ILCA. La Paz.

22 Elvira Espejo Ayca nació en Qaqachaka y ahora vive en La Paz. Es artista plástica, tejedora, poetisa y hablante de quechua y aymara. Desde hace varios años es investigadora regular de ILCA. A inicios del 2013 fue elegida como la nueva directora del Museo de Etnografía y Folclore (MUSEF), de La Paz.

23 Arnold, D. y E. Espejo Ayca. 2010. Ciencia de las mujeres. Experiencias en la cadena textil desde los ayllus de Challapata. Fundación Albó-ILCA, La Paz.

24 Arnold, D. y E. Espejo Ayca. 2012. Ciencia del tejer en los Andes: estructuras y técnicas de faz de urdimbre. ILCA, La Paz.

25 Arnold, D. y E. Espejo Ayca. (en prensa) El textil tridimensional: Ia naturaleza del tejido como objeto y como sujeto. ILCA, La Paz. En el marco de esta serie de libros dedicados a la dimensión técnica del 
sobre la complejidad tridimensional del textil, que tiene que ver con el desarrollo intelectual de la tejedora como persona y su habilidad de pensar en muchas dimensiones del mundo al mismo tiempo.

FP: En ese proceso ¿cómo fue el trabajo con las tejedoras? En el caso de Elvira Espejo, es coautora ${ }^{26}$, ¿pero en relación al resto de las mujeres?

DYA: Recuerdo que en los años de trabajo de campo intensivo siempre llevábamos "lanitas" para las niñas. Era el mundo de la lana acrílica en aquellos años, todas las mujeres querían eso y las niñas querían esos ovillitos de lana para sus primeras prendas. Era un modo de diálogo, de intercambio con ellas. Y durante aquellos años, las tejedoras de Qaqachaka siempre me pidieron proyectos de salud y educación, y sobre todo un proyecto textil. Entonces, primero hicimos un proyecto práctico sobre los textiles en la región, de tipo ONG. Elvira también estaba muy motivada para ver cómo se podía sistematizar la cadena de producción textil en la región en corto tiempo. Hemos trabajado en conjunto tratando de sistematizar todas las etapas de la cadena y usamos eso para organizar los talleres prácticos con las mujeres. Fue muy interesante lo que ha pasado, porque en esos talleres las mujeres recordaban todas las etapas de la cadena, con lágrimas. En aquellos años era casi parte de su pasado, yendo al olvido. Ellas trabajaban más con Elvira, mientras yo manejaba el auto y practicaba mi aymara y apoyaba. Pero Elvira realmente ha traducido toda la terminología material de la cadena de producción, al quechua y aymara, para que las participantes entiendan fácilmente cómo mejorar la finura textil en cada etapa. Y les conmovía. En otro proyecto académico posterior trabajamos con las colecciones museológicas de textiles de los Andes en el Reino Unido y en América Latina, y pudimos comparar la calidad más fina de los textiles arqueológicos con los instrumentos que se usaban, que eran muy diferentes de los actuales. La rueca para hilar que se usa actualmente es grande pero en los museos son muy pequeñas. ¿Por qué? Es porque cuando se hilaba con estos instrumentos pequeños jel hilo salía mucho más fino! Esto ha sido una de las ideas que Elvira llevó a la práctica: tratamos de reducir el tamaño de las ruecas que usaban las mujeres y en un mes las mujeres mayores ya estaban produciendo hilos muy finos. Fue un proceso de aprendizaje tan fascinante que en dos años pudimos desarrollar textiles de calidad, tratando de "rescatar" algunas prendas históricas de la región en calidad de bienes para la venta. Esto ayudaba a las mujeres a mejorar sus ingresos, porque había problemas muy serios de

textil también se encuentra: Arnold, D. y Penny Dransart (eds). (en prensa). Textiles, technical practice and power in the Andes. Archetype, Londres.

26 Recordemos que la experiencia de Denise trabajando en colaboración con miembros de las comunidades también se remonta a las publicaciones que posee junto a Don Domingo Jiménez Aruquipa: Hacia un orden andino de las cosas..., de 1992, y Madre melliza y sus crías..., de 1996, ambos ya mencionados. pobreza en la región de Qaqachaka. En otras regiones como en las islas del Sol y de la Luna, donde trabajamos un corto tiempo, las mujeres querían recuperar la tradición textil para contribuir a sus ingresos del turismo. El proyecto fue un éxito y nos invitaban a exponer en la $\mathrm{CAF}^{27}$ y en lugares internacionales. Escribimos el libro Ciencia de las mujeres como un recuerdo de estos procesos de recuperación y cambio de calidad, de modo de señalar a otros municipios cómo se podía replicar este proceso en diez pasos. El libro es muy didáctico y escrito en un lenguaje sencillo, porque las mujeres nos lo pedían así. El libro está dirigido a todo el Altiplano. El problema es que desde la entrada de Evo [Morales], no hubo imaginación para desarrollar un plan productivo de este tipo dirigido a las comunidades rurales del Altiplano; el único plan de desarrollo parecería que fue la producción de cocaína. Los políticos entraban en la zona y les daban permiso para generar esta producción sin molestias, para ganar lo que pudieran en pocos años. Eran como políticas dirigidas a aliviar la extrema pobreza y en este sentido tenían éxito, porque ya no hay pobreza económica en la región, se ha borrado. ¡Ya son millonarios! Las familias que conocía con sus rebaños en sus corrales ya andan con dos o tres Mitsubishi, parqueadas fuera de sus casas jen vez de los animales en los corrales! Primero, se pudo desarrollar suficiente capital en la región de Challapata mediante el ingreso de los autos chutos $^{28}$ de Chile, en situaciones muy peligrosas para los jóvenes. Luego se usaba este capital para comprar la maquinaria y finalmente se producía la pasta base. Socialmente, este proceso fue muy destructivo. Se ha convertido toda la región de Challapata en actividades criminales, con un acelerado nivel de violencia armada. Yo diría que se ha destruido la vida de toda una generación. Ahora, cinco o seis años después, se ha vivido un largo período de contar con ingresos mensuales de mil dólares por mes por familia, sobre todo en manos de los varones. Lo curioso es que lo que las mujeres quieren hacer con este dinero en sus manos es tejer. Ellas han "craneado" durante mucho tiempo toda la sistematización de la cadena textil que hicimos con ellas durante los talleres de 2006-2009, y ahora las que asistieron a los talleres actúan como mamaconas ${ }^{29}$ y enseñan a otros grupos de mujeres más jóvenes cómo se debe tejer más finamente. Actualmente, en la región hay novecientas familias y unos 50 varones que tejen, y todos están tejiendo por gusto. Ahora en vez de contar con la caja chica familiar que eran sus ovejas, ellas compran lana muy fina y de buena calidad, en la ciudad de Oruro, y luego producen textiles de alta calidad que venden al mercado extranjero por dólares. Es un ingreso modesto

\footnotetext{
27 Durante 2010, Elvira Espejo Ayca realizó exposiciones en el Artespacio CAF (Corporación Andina de Fomento), en La Paz.

28 Chutos son los autos indocumentados que ingresan clandestinamente al país para ser vendidos.

29 El término mamacona refiere inmediatamente a las encargadas de enseñar y controlar la producción textil en los tiempos incaicos; en este caso, el sentido es similar, enfatizando la función pedagógica de las mujeres tejedoras.
} 
pero impactante para ellas, puesto que los hombres no comparten mucho el dinero que acumulan: ellos están más metidos en el partido y viajan con asuntos políticos. Pero las mujeres viven constantemente en el ayllu y en vez de tener sus ovejas como antes ahora han vuelto a criar camélidos y a usar su fibra para los textiles. Se ha pasado por todo un proceso que tiene sus lados muy negativos, con mucha violencia, en un cambio total en la vida rural. Sentimos mucho esta experiencia como observadores de estos cambios en familias que conocemos y con personas que hemos conocido desde changos. Muchas de las cosas que hemos escrito en los años '80 y '90 ya no existen. Los cantos a los animales, todo ha desaparecido. Hay una intromisión del partido oficialista y sus políticas en la radio comunal, con llamadas por un camino de desarrollo de tipo soviético. Se rechaza por estos medios cualquier asunto indígena, a pesar del modelo y del discurso que se conoce a nivel mundial y en Le Monde Diplomatique. En la realidad es lo contrario: borrar lo más pronto posible el mundo indígena del pasado. Pero a pesar de todo ello, las mujeres de la región están produciendo textiles iy haciendo desfiles públicos con sus nuevos productos! Para mí, esta experiencia es otra prueba de que ese mundo de lo "andino" no existe. En lugares como Qaqachaka hubo un repliegue estatal durante dos siglos y se desarrolló una forma de vida muy dura para sobrevivir, con memorias del pasado combinadas con inventos constantes de la tradición desde la actualidad. Pero aquella vida era muy vulnerable a ese tipo de intromisión política y económica, y pudo cambiar en unos años, dramáticamente. Antes de este nuevo ciclo económico hubo procesos muy rápidos de migración de la gente joven fuera del ayllu hacia las ciudades. Actualmente, muchos residentes en las ciudades están regresando al campo para aprovechar estos logros económicos. Lo más irónico de todo es que ellos describen la nueva cadena de producción que manejan como una cadena comunal... Muchos de los textos de los años '70 y '80 no nos ayudan a entender estos procesos, ni los riesgos que estas poblaciones aguantan para salir de la pobreza económica. Porque después de salir de los ciclos viciosos anteriores de la pobreza, ¿qué? Si no hay buena educación y buena salud... Yo diría que hay un gran vacío en las propuestas teóricas de los últimos 30 años, si uno mira críticamente la literatura. Mucha es obsoleta. En parte, ya diría la aceptación de esa literatura por parte de la clase media boliviana, sin crítica, fue parte de una construcción romántica hacia lo indígena, sin la mínima intención de cambiar la situación política o compartir los recursos económicos del país.

FP: Y en términos de debate antropológico-teóricopolítico actual, ¿cree que el textil puede ser una vía de entrada para comprender ciertos aspectos de los Andes que aún no han sido explorados? ¿Una forma de repensar lo "andino" y a la vez un modo de que la antropología andina ingrese a los debates de la etnología contemporánea?

DYA: Sí, el textil, la cultura material y los estudios de los flujos de bienes, son todos temas que se pueden debatir a nivel mayor, como alternativa al indigenismo cerrado actual. En otra coyuntura se podrían incentivar diálogos sobre estos temas. La sistematización de los procesos de elaboración textil se puede aplicar en el sistema educativo y se puede aplicar intelectualmente a la minería y a muchas otras áreas productivas, como la comida, que quedan por explorar debidamente. Hay muchas puertas de comprensión del textil. En el caso de la minería, hay también una serie de nexos importantes históricamente con la producción textil: hay relaciones entre las transformaciones de los minerales y de los tintes, hay muchos aspectos de un lenguaje en común y uno sospecha que todo ese mundo está ahí por explorar. Hemos conversado con Heather Lechtman, experta en el estudio de la metalurgia en los Andes, y ella quería explorar estos nexos, pero no tuvo tiempo. Entonces en algún momento deberemos formar estudiantes para hacerlo.

FP: Y para terminar con la comparación Andes-Amazonía, la sensación es que tal vez las diferencias entre ambas antropologías se vinculan a los linajes teóricos de cada lugar. Tal vez para Amazonía se trabajó en el marco de macroconceptos, como el de "cosmología", que al ser muy holísticos permitían que distintos tipos de registros operaran simultáneamente y todo debiera ser explicado en relación a otros temas. En cambio, tal vez en la antropología andina hay muchas cosas interesantes pero cada una en su lugar.

DYA: Claro, me parece que los estudios de la "cosmovisión", como se llama en los Andes, son demasiado teóricos y demasiado colonizado por los curas. No se vinculan fácilmente con lo material, lo económico, lo productivo, y otros registros, ni con las necesidades de la región o la vida cotidiana. Es algo que habría que hacer a un nivel menos académico también. Mi esperanza es que tenemos algunas pautas ahora para desarrollar estos macroconceptos, pero por vías distintas: entrando desde la tecnología, desde el mundo tecnológico y desde nociones de la ciencia en general. Esto es muy pertinente en la coyuntura actual y en el contexto de las nuevas direcciones señaladas por pensadores como Arjun Appadurai, Bruno Latour, Tim Ingold... En la introducción del último libro, El textil tridimensional, examinamos el desarrollo económico de la familia Toyosa en Japón, quienes comenzaron con la producción de telares y telas, y en base a ella pasaron a la industrialización del automóvil. Son muy interesantes los nexos entre los desarrollos del textil y la industria de motores, y entre el textil y la computadora. Abre el espacio hacia la historia social de la ciencia. Hicimos una historia de este tipo en un capítulo sobre la $k^{\prime} i s a^{30}$ como degradeé de color, tratando de deshacernos de algunos clichés de los estudios de los años

\footnotetext{
30 Las k'isas son degradaciones de colores que se logran mediante el teñido de los hilos. La degradación es un efecto que puede efectuarse en diferentes tipos de textiles y el distintas partes del mismo, constituyéndose parte de la "identidad" de muchas prendas
} 
'70 y revinculando la k'isa con la introducción de los tintes de anilina de Europa, en el siglo XX, y posteriormente con la de la lana acrílica de México, en los años '60. Creo que es hora de dejar de antropologizar los Andes y abrir los estudios antropológicos a temas reales; si no, caemos en los clichés de que los indígenas no tienen nada que ver con la modernización, la modernidad o el capitalismo, que es algo ridículo. Nosotros hemos tratado de hacerlo por algunas vías más tangibles, que permitan una visualización de lo que está pasando. Al mismo tiempo, como tú dices, en Brasil se puede relacionar distintas subdivisiones disciplinarias con un modelo teórico articulador. En Bolivia, la situación económica no permite el lujo de reflexionar sistemáticamente sobre estas cosas. Aquí uno tiene que meterse en varias disciplinas por el problema del trabajo. La universidad paga poco y tienes que meterte en proyectos constantemente para poder sobrevivir. Así son los intelectuales en Bolivia, por necesidad. No hay espacios de investigación para juntar y comparar datos o para reflexionar a nivel mayor. Además, hay una carencia de trabajo de campo serio. Pocas personas quieren hacerlo. En el proyecto sobre textiles tuvimos que formar algunos arqueólogos en Bolivia en el tema del textil, y esto ha sido muy difícil porque ellos no entienden nada de aymara y quechua, y saben poco de la vida del campo, no les interesa tampoco. Además nadie estudia el textil. El cliché para ellos es que el textil sólo se preserva en la costa, cuando hay cuevas secas con metros sobre metros de restos de tejidos en pleno Andes.

\section{FP: ¿Y para el futuro? ¿Cuáles son las perspectivas?}

DYA: Necesito un poco de tiempo para pensar primero y luego desarrollar algunos ensayos sobre temas que han llamado mi atención en los últimos años, pero que no he podido explorar debidamente: la iconografía en general, las iniciativas de ciencias alternativas, los textiles en otras partes del mundo, una serie para televisión sobre los textiles de los Andes en sentido amplio... Hay muchas cosas para hacer, pero hay que ir armando proyectos de investigación para poder examinar las cosas que uno quiere. Tenemos un plan para un pequeño proyecto con Juan de Dios y Elvira en los museos de Bolivia, para documentar mejor las colecciones, organizar exposiciones sobre las técnicas textiles en cada colección y trabajar entre grupos de artesanos, curadores e investigadores, en nuevas iniciativas. Eso sería interesante.

La Paz, 11 de septiembre de 2012 